\title{
An Investigation into the Effectiveness of Digital Convergence in Student Learning and Engagement
}

\author{
Bobbi Makani \\ San Jose State University \\ Carol Easter \\ Chabot College \\ Marilyn K. Easter \\ San Jose State University
}

This study investigates the effectiveness of a new course redesign using technology delivered across various mobile platforms. This study documents the process of the course redesign to present a viable model for redesigning courses that will increase student engagement using technology. Assessment data from several marketing classes over a number of semesters was used to compare results from other marketing classes conducted using the traditional mode with minimal technology. The results indicated better overall student performance across the classes. Recommendations to scale the process include a multi-sectoral approach to the redesign and support for faculty professional development.

Keywords: Digital Convergence, Student Learning, Technology, Engagement

\section{INTRODUCTION}

Digital convergence brings opportunities and challenges in higher education. In some cases, mobile devices allows for access to multiple sources of information as easily as it allows for access to information that may easily disrupt learning. When implemented properly, digital convergence holds the potential to increase student learning and engagement, where traditionally, learning as well as sources for learning was in the hands of the instructor.

Decades ago, digital learning in the form of online or hybrid modality was not viewed as a likely alternative mode of learning that would displace traditional forms of education (EDUCAUSE, 2015; Keohane, 2013). Today, the outlook is very different. Successful and robust online courses are being delivered and many more are in the process of development (Allen \& Seaman, 2011, 2013, 2015; Anderson \& McGreal, 2012, DeSilets, 2013). Popovici \& Mironov's (2014) survey indicated 325 students reported that more than $62 \%$ of them spend between 5 to 10 hours daily using various online technologies and $98.11 \%$ have medium to advance expertise computers or laptops. When instructors have a positive

attitude about using technology as an instructional tool, can achieve a higher degree of successful learning 
outcomes in their classes. Many educators feel confident that online learning will continue to account for a larger share of the way instructors teach and students learn in the coming years (Desilets, 2013; Gwynne, 2103).

According to EDUCAUSE Learning Initiative (2013), advancements in technology and media convergence will continue to influence and affect online learning. Digital bandwidth, computers and digital devices continue to evolve, and online learning will progress as well. The advent of the Internet and the surge in the use of technology in education over the past decade has made it possible for colleges and universities to offer online courses. More importantly, access to different types of media helps students access learning anywhere they are at any time of the day. Knowing how to use different types of media gives students a modern skill set that many employers find desirable in potential employees (Chamberlin, 2014). These skills include digital literacy, online communications, research ability, and computer use. Online learning also helps develop self-discipline, time management, motivation and initiative, which are real world skills that employers value and look for in potential hires.

\section{BENEFITS AND CHALLENGES OF DIGITAL CONVERGENCE IN ONLINE LEARNING}

Media convergence is a communications theory in communications where every medium eventually merges with one another to a point when the different types of media are no longer distinguishable from each other. A new type of medium is created from this synthesis and is made available with the use of new communication technologies. With the advent of this new medium over the internet, media convergence is fast becoming a reality. The society already experiences this in media and entertainment and media convergence is now making its presence felt in higher education through multiple tools used for delivering digital course content.

Studies showed that the current generation of learners prefer online or blended formats delivered across different types of media because it affords greater time flexibility, freedom and convenience to work on their courses (Hogarth, 2010; Torrisi-Steele \& Drew, 2013; Comey, 2009). Online access reduced geographic constraints, increased availability of course materials, and improved the quality of learning so that students are better prepared for lifelong learning (Jacob, 2016; Subhashia, 2008). Online learning provided students the ability to interact more with the instructors because of the numerous opportunities available for communication (Comey, 2009; Folley, 2010), i.e., emails, online discussion forums, chats, podcasts, and posts on social media.

In addition, students can access course materials via many online platforms from the comfort of their chosen learning space (Norman, 2016). Set up correctly, the online learning environment enabled students the ability to pace themselves in the learning process (Jacob, 2016) and express themselves through the creation of digital content such as online media, podcasts, and video casts and sharing these with the instructor and their peers.

As the field of education moved from traditional learning modes to new approaches, it would be worthwhile to pay attention to the relationship between the modes of the delivery of course content, and student learning and engagement. Students enrolled in any course, whether traditional face-to-face, hybrid or blended learning, or online learning environment, generally expect to have some sort of interaction with their instructor (Lear, Isernhagen, LaCost, \& King, 2013). Interaction fosters learning (Cao, Griffin, \& Baj, 2009), and in this context, media convergence becomes a critical factor in the success of the online learning experience. Using different types of media, students can now access course materials and interact with the instructor outside of regular class hours.

Digital learning has its challenges and, often, these are in the areas of technology competence, student expectations and motivations, and time management (Torrisi-Steele \& Drew, 2013; Rothrauff, 2011; Simonson, Smaldino, Albright \& Zvacek, 2003; Sorden \& Munene, 2013). It is required that all the participants in the course, the instructor and students, possess the minimum technology skill level to effectively participate in the class. An instructor who does not have adequate technology skills would find it very difficult to design an effective online learning course (Belair, 2012; Alexander \& Levine, 2008). On the part of the students, not having the required technology skill set would likewise pose a challenge 
in terms of going through and keeping up with the course (Valenti, 2015). The design of the course, timemanagement, comfortability with online technologies, affect the success of the student learning experience (Liyan, Singleton, Hill \& Koh, 2004). Students that are less motivated, poor performing, disengaged, or reluctant learners are also a challenge in the online environment (Jacob, 2016).

\section{LITERATURE REVIEW: DIGITAL CONVERGENCE IN HIGHER EDUCATION}

The internet has made it possible for students to access digital information in ways that were never thought possible. Much of the change is driven by learners who seek to control what they want to see, when and how they want to see it. This level of control is already embedded in the convergence of technological factor such as online access to course materials, digital assignments and communication at a touch of the button. New generation smartphones, powered with computer chip technology that fits on the tip of our fingers, takes all learning into the mobile space.

The evolution of convergence in higher education can be traced back to the transformation of information distribution and consumption (Köse, 2010). Decades ago, knowledge is "dispensed" in the more traditional face-to-face encounters in the classroom. The internet ushered in wider access to information through flexible digital processes. In their study, Bennett et al (2012) concluded that the use of a variety of platforms has become the norm in the commercial news distribution process. For educators in colleges and universities, the focus is on transforming traditional delivery of the curriculum into a new digital system that may be difficult to grasp. Some educators wonder whether or not they have the necessary skills to accomplish this. With more information made available on the digital superhighway, there is no doubt that the delivery of the curriculum through traditional and conventional methods may not be of much value in the converged world (Bennett et al. 2012).

The quantitative results of Hersh's (2009) research demonstrated that students enrolled in the mediaenhanced environments and who had access to course content had higher levels of course satisfaction and tended to complete them with higher academic scores than students in traditional environments. The results of his study indicated that even at the onset of the digital convergence, students already exhibited greater engagement with various forms of media. The study showed that a statistically significant difference existed between the mean scores of both groups to suggest that students were more satisfied in the media-enhanced human presence online classroom versus the traditional environment. The results further indicated students enrolled in the media-enhanced environment were more likely to complete the class than those enrolled in traditional environments. Students exposed to the media-enhanced human presence online classroom had a completion rate of $69 \%$ versus a completion rate of $64.2 \%$ for the traditional environment.

\section{METHODOLOGY}

Marketing is an extremely dynamic field and this environment has to be brought into the classroom for students to appreciate the practice. The course, Principles of Marketing, was selected for this study due to its foundational nature and the need to redesign the course to adapt to the real world. This marketing course provides a general introduction into the fundamental principles of Marketing and for most students, their first foray into the field. Several aspects of the Marketing course were redesigned for this study. In the process, the current curriculum was examined and dissected to see where the redesign can take place and have the greatest impact. It turned out that the entire course had to be redesigned in a way that different technologies such as media, content, services and applications can be utilized by students in the course. In the redesigned course, significant use of Open Education Resources (OER), will be used. OER eBooks and other eMaterials are integrated in Canvas Modules as part of the redesigned learning environment. The most essential chapters are selected from three different OER textbooks, which are all available for free. Print textbooks are recommended if students prefer to have a print resource for key marketing concepts. The three OER eTexts are the primary source materials. Students will have the same quality materials provided by publishers. 
The course was designed to be delivered in modules that start with a mini recorded lecture on what students are expected to learn. The recorded lecture clearly articulates the learning outcomes for each module. Links to external learning resources are embedded in Canvas. The course is designed so that students know that their course materials can only be opened through Canvas. With a single click, students are able to access all course materials which were taken from different sources. Foundational marketing concepts are covered in all modules to promote higher order thinking skills that are essential to marketing. The redesigned course focuses on specific chapters and concepts to ensure that students gain a deeper understanding the fundamental concepts of marketing. The guiding principle in designing this course is "Less is More".

The course is laid out in 7 vertical modules so that students can easily work through the information and concepts step-by-step. The assessments in each module is standard. Each module introduces the students to what they can expect from the reading materials, the learning outcomes, and the expectations of what they should learn at the end of each module. Additional resources from various sources are integrated into the course. Recorded lectures from YouTube Education, Khan Academy, TedEx and other credible sites were included. The designed discussion questions were also designed so that students can optimize the use of the available resources from different types of media and engage themselves with the learning material. The discussion environment was designed to contribute to the engagement of the students with their peers.

\section{ASSESSMENT FINDINGS AND RESULTS}

This section presents the results of the redesigned course implementation over several semesters. The course was delivered in seven flowing modules that made it easy for students to understand the marketing concepts and theories. The students have access to a free online textbook made available through the open education resources websites such as Cool4Ed and Merlot. The instructional designer worked closely with the instructor to bring various digital resources into the course that will help students understand the concepts better. To assess learning outcomes, each module had assessment pieces that relate directly to the learning outcome for that specific module. The modules were set up with enough time for students to master the concepts before moving on to the next topic in the course. The assessment given to the students ensured that they are able to exhibit competence in areas that matter. Table 1 shows the actual student final grades for the pre-redesign (old curriculum) and the redesigned courses.

\section{TABLE 1}

\section{ACTUAL STUDENT FINAL GRADES FOR PRE-DESIGN AND REDESIGNED COURSES} (AY1, AY2, AY3) N = 275

\begin{tabular}{|c|c|c|c|c|}
\hline Grades & $\begin{array}{c}\text { Pre-Redesigned } \\
\text { Course }\end{array}$ & $\begin{array}{c}\text { Redesigned Course } \\
\text { (AY1) }\end{array}$ & $\begin{array}{c}\text { Redesigned Course } \\
\text { (AY2) }\end{array}$ & $\begin{array}{c}\text { Redesigned Course } \\
\text { (AY3) }\end{array}$ \\
\hline A & 0 & 0 & 3 & 3 \\
\hline A- & 0 & 3 & 5 & 7 \\
\hline B+ & 2 & 3 & 2 & 15 \\
\hline B & 2 & 4 & 7 & 25 \\
\hline B- & 8 & 5 & 12 & 13 \\
\hline C & 12 & 4 & 12 & 12 \\
\hline C & 6 & 2 & 10 & 18 \\
\hline C- & 4 & 3 & 16 & 10 \\
\hline D+ & 2 & 0 & 3 & 9 \\
\hline D & 2 & 1 & 4 & 5 \\
\hline F & 3 & 3 & 3 & 0 \\
\hline W & 3 & 0 & 0 & 0 \\
\hline I & 0 & 1 & 0 & $\mathbf{1 2 5}$ \\
\hline Total & $\mathbf{4 4}$ & $\mathbf{2 9}$ & $\mathbf{7 7}$ & \\
\hline
\end{tabular}


Figure 1 shows the grade distributions for the pre-redesigned (old curriculum) and the redesigned courses. The results showed that there were more students getting higher final grades in the redesigned course than in the course delivered in the old curriculum.

\section{FIGURE 1
GRADE DISTRIBUTIONS: PRE-REDESIGN VS. REDESIGNED}

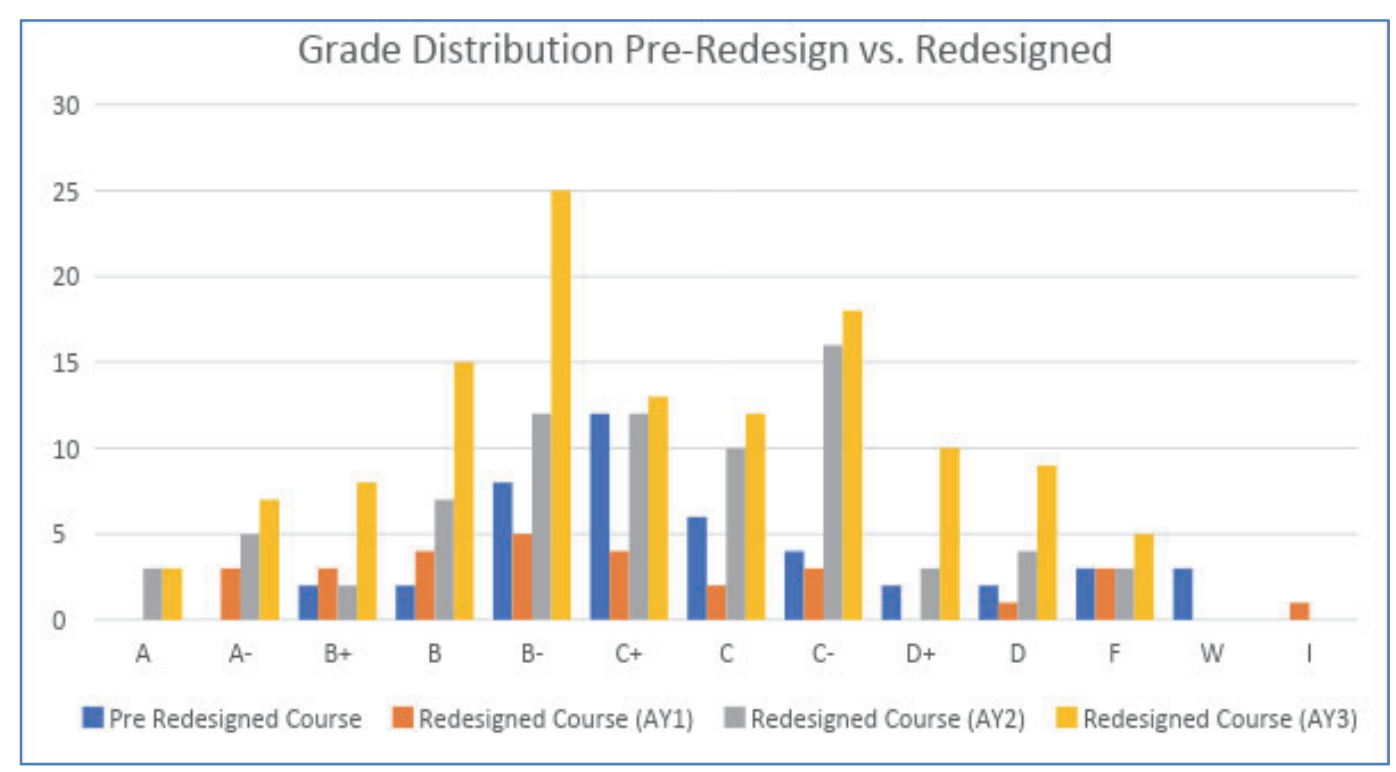

Figure 2 shows the grade percentage comparisons between pre-redesign and redesigned courses for several sections of the basic marketing course.

FIGURE 2

GRADE PERCENTAGE COMPARISONS: PRE-REDESIGN VS. REDESIGNED

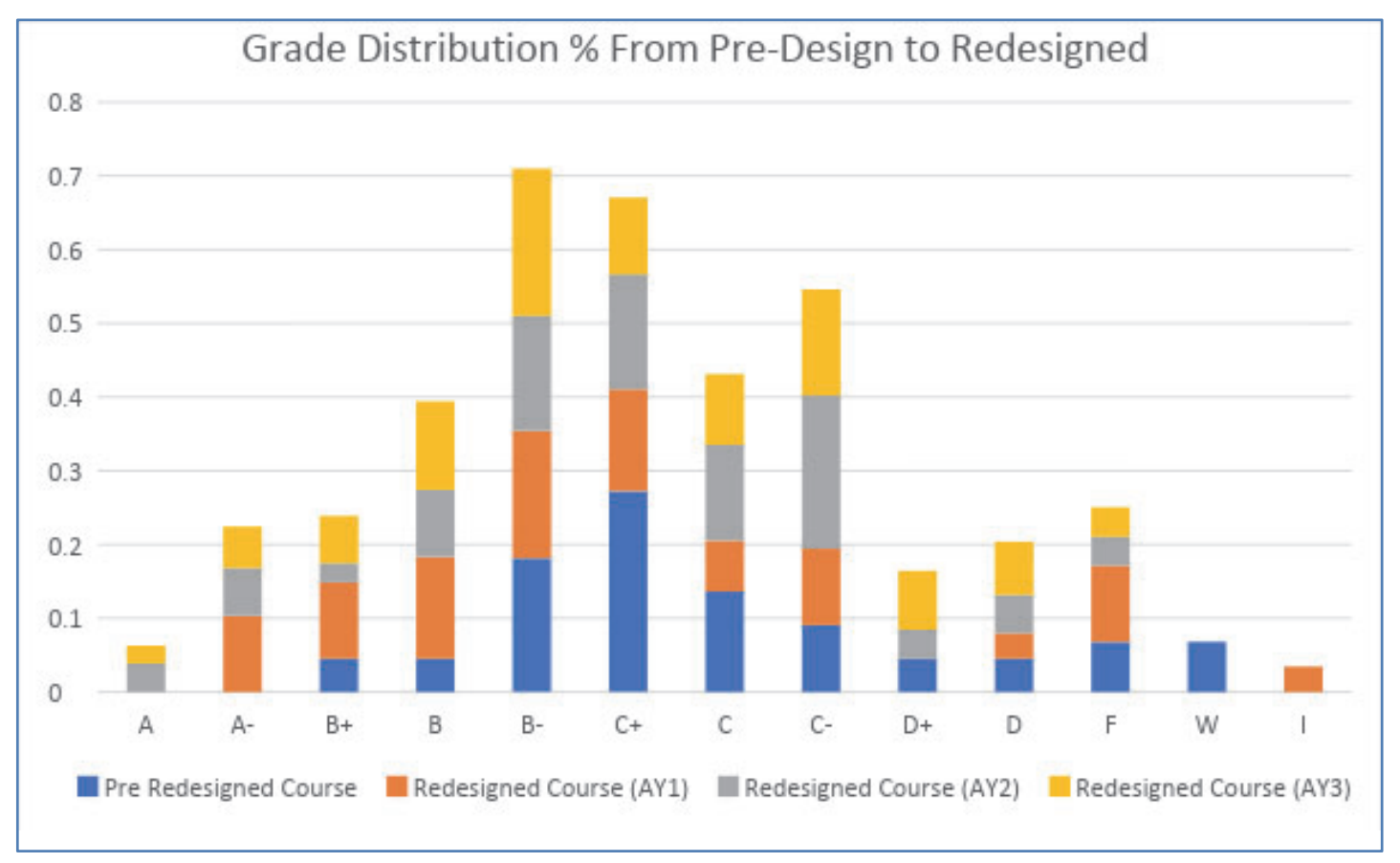


FIGURE 3

PASSING AND NON-PASSING STUDENT COMPARISONS -

PRE-REDESIGN VS. REDESIGNED

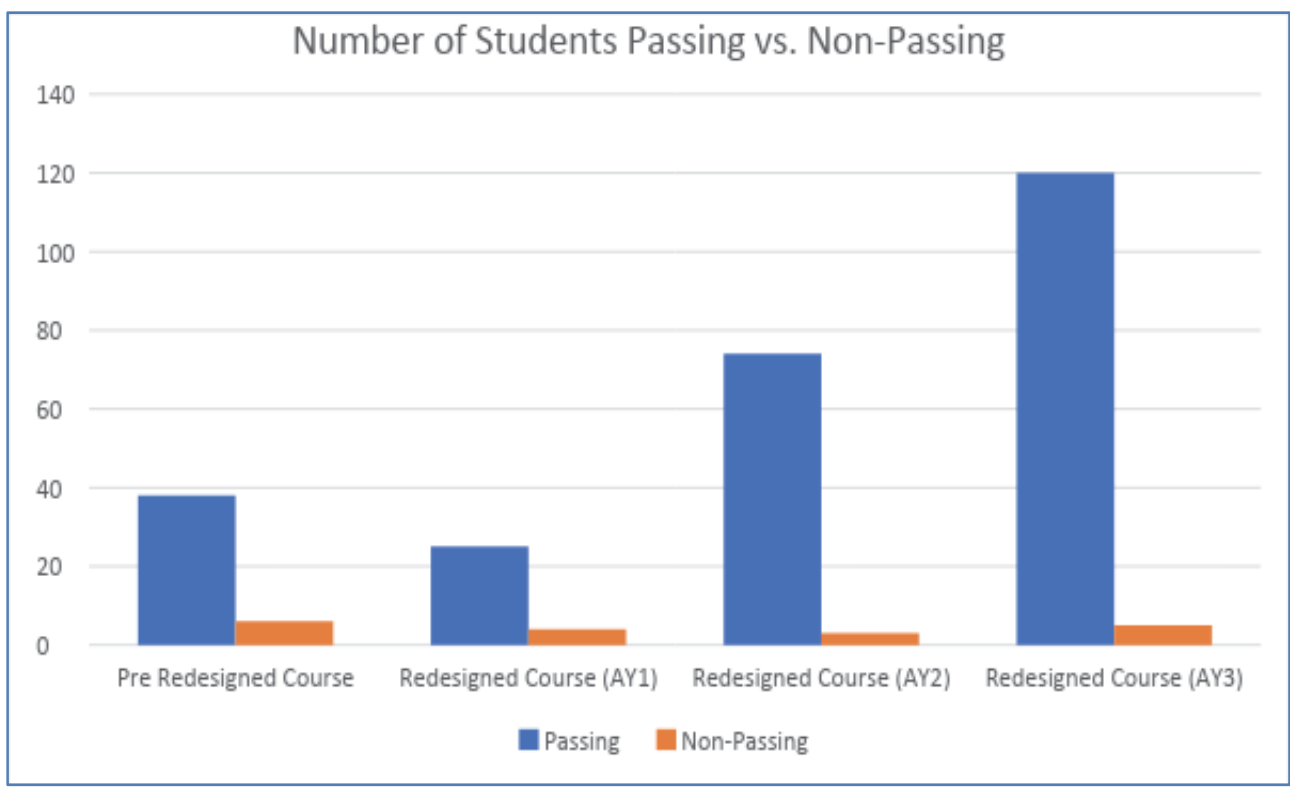

FIGURE 4

PASSING AND NON-PASSING STUDENT PERCENTAGES

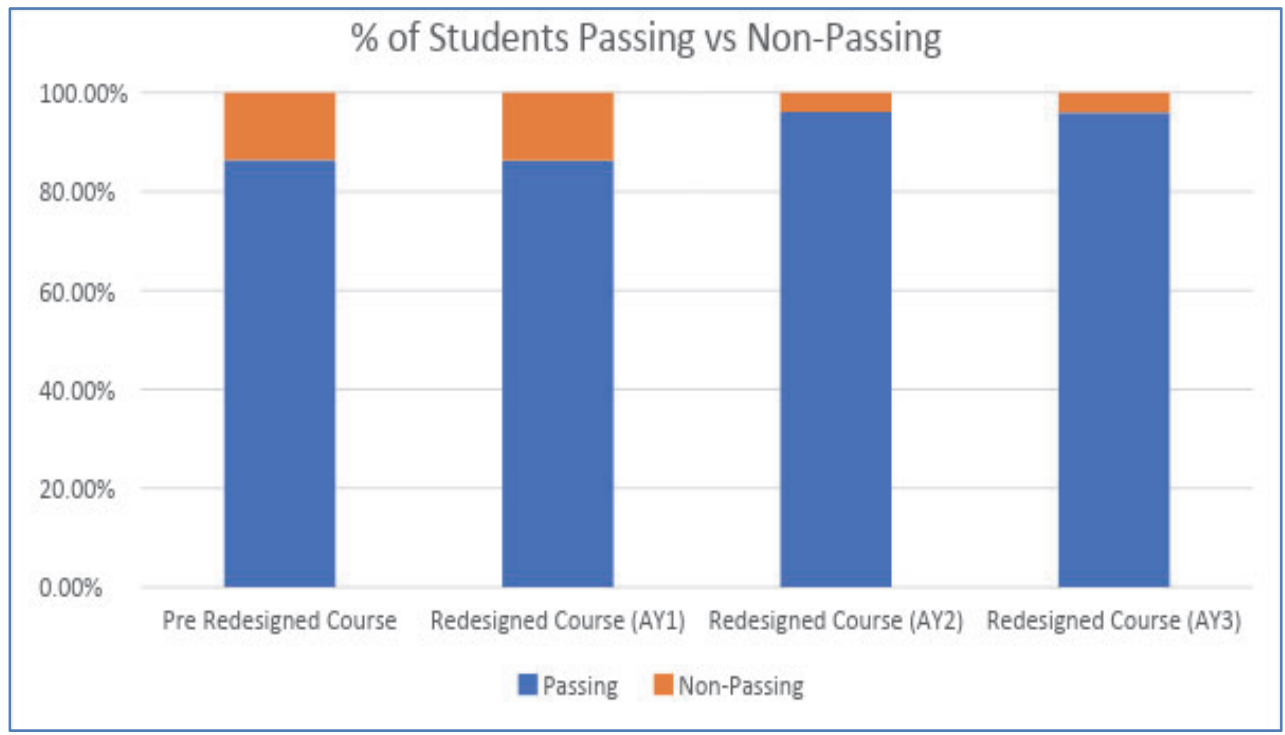

\section{DISCUSSION}

The results from several semesters of evidences support our initial findings that student from the redesigned courses show better performances. In terms of learning, the new redesigned course helped increase student engagement with course as evidenced by the skew towards higher grades. More students in AY2 and AY3 of the experiment are receiving A level grades. There was a higher percentage of students passing the course. Instructors also had a greater engagement with teaching as the redesigned 
course helped the instructor focus on the teaching aspect by curating various digital resources from the internet and building on top of these readily available resources. The course redesign strategy solved many of the issues with access to a single textbook and materials by making use of the information available through digital convergence.

Students were more engaged in the course and the learning activities when they have access to the material through different platforms. They could easily see the connection between the concepts they are learning and its application since this is delivered in a platform that they are familiar with. This was achieved through sharing videos and digital resources that particularly related to the concepts they are learning. The modules enabled the instructor to focus on the marketing concepts and go deeper into the materials that are prescribed by a single textbook.

This study of digital convergence in higher education has just barely touched the surface of the complexity of factors that contribute to student learning. However, there is a push to utilize various media platforms as the $\mathrm{Z}$ generation of students start coming into classrooms of universities and colleges across the globe. The intent of this study is to establish that the new generation of teaching and learning is already starting. It is critical to engage students through platforms that they are familiar with.

Unlike the students, current higher education instructors are non-digital natives. Hence, the need to put in place a path for professional development to get instructors up to speed on the digital learning environment. Most instructors may not realize it, but they may not have the necessary knowledge and training in the world of digital convergence. Professional development with focus on how to effectively find and curate credible digital resources and use these to link concepts to applications will help students get more engaged in their learning. There are numerous opportunities for exploring the digital convergence and how this is used in higher education. As colleges and universities welcome the new millennial and Generation $\mathrm{Z}$ into the classrooms, there is a need for instructors to engage the students in the environment these new students thrive in - digital. Here is where the need for innovative approaches to learning and knowledge on navigating the digital landscape will be increasingly important for instructors.

Higher education institutions will need to provide resources to train faculty on how to best engage student in the digital works and interact with them. Instructors should shift their focus to course redesigns and how they might best integrate digital tools such as forums, discussions, feedback and responses into their courses to better engagement students. From an institutional perspective, faculty success divisions should work out incentive plans for instructors to help them redesign their courses for various types of modalities that can be launched in multiple platforms.

There are still questions to be answered that would bear valuable results in future research for all stakeholders in higher education. Some suggested areas for future research include: 1) Further studies to determine the impact of digital convergence in teaching. This would help faculty in rethinking and redesigning their courses and plan for its delivery. Knowledge of how to weave in digital resources would engage students in their learning would help faculty provide a more enhanced experience within the online learning environment. 2) Identify opportunities and design programs for faculty to engage in professional development training that would more adequately meet the diverse needs of these instructors, whether they are new to the digital world or at its cusp. As the winds of digital convergence continue to swirl around higher education, creative and innovative approaches to learning will be increasingly important. 


\section{REFERENCES}

Alexander, B., \& Levine, A. (2008). Web 2.0 storytelling. Emergence of a new genre. EduCAUSE Review, 42(6), 40-56.

Allen, E. I., \& Seaman, J. (2011). Going the distance: Online education in the United States, 2011. Babson Survey Research Group. Retrieved from Online Learning Consortium: http://www.onlinelearningsurvey.com/reports/goingthedistance.pdf

Allen, E. I., \& Seaman, J. (2013). Changing Course: Ten Years of Tracking Online Education. Babson Survey Research Group. Retrieved from Online Learning Consortium: http://sloanconsortium.org/publications/survey/changing_course_2012

Allen, E. I., \& Seaman, J. (2015). Grade change: Tracking Online Education in United States, 2011. Babson Survey Research Group. Retrieved from Online Learning Consortium: http://www.onlinelearningsurvey.com/reports/gradechange.pdf

Anderson, T., \& McGreal, R. (2012). Disruptive pedagogies and technologies in universities. Journal of Educational Technology \& Society, 15(4), 380.

Belair, M. (2012). The investigation of virtual school communications. TechTrends, 56(4), 26-33. doi:http://dx.doi.org/10.1007/s11528-012-0584-2

Bennett, S., Bishop, A., Dalgarno, B., Waycott, J., \& Kennedy, G. (2012). Implementing Web 2.0 technologies in higher education: A collective case study. Computers \& Education, 59(2), 524534. doi:10.1016/j.compedu.2011.12.022

Cao, Q., Griffin, T. E., \& Bai, X. (2009). The importance of synchronous interaction for student satisfaction with course websites. Journal of Information Systems Education, 20(3), 331-338.

Chamberlin, W.S. (2014). The teleweb: Meeting diverse learning styles with active learning. e-Learning Conference.

Comey, W. L. (2009). Blended learning and the classroom environment: A comparative analysis of students' perception of the classroom environment across community college courses taught in traditional face-to-face, online and blended methods. The George Washington University. ProQuest Dissertations and Theses, 165. Retrieved from http://search.proquest.com.er.lib.kstate.edu/docview/288045934? accountid=11789. (288045934).

DeSilets, L. D. (2013). A revolutionary journey into learning/education. The Journal of Continuing Education in Nursing, 44(1), 8-9. doi: http://dx.doi.org/10.3928/00220124-20121227-69

DeSilets, L. D. (2013). No longer a passing fad. The Journal of Continuing Education in Nursing, 44(4), 149-150. doi: http://dx.doi.org/10.3928/00220124-20130327-92

EDUCAUSE. (2015). Distance Education Enrollment Growth Continues. Retrieved August 5, 2015, from http://onlinelearningconsortium.org/news_item/babson-study-distance-education-enrollmentgrowth-continues/

Folley, D. (2010). The Lecture is Dead Long Live the e-Lecture. Electronic Journal of E-Learning, 8(2), 93-100

Gwynne, P. (2013). A fresh twist on online learning. Research Technology Management, 56(1), 6-7. Retrieved from: http://search.proquest.com.er.lib.kstate.edu/docview/1315649818?accountid=11789

Hersh, D. E. (2009). Human factors: Increasing online student satisfaction, class completion and academic achievement through human presence design (Unpublished doctoral dissertation). Argosy University, Orange County.

Hogarth, A. (2010). Education in a competitive and globalizing world: Adopting blended learning for collaborative work in higher education. (1ed.). New York: Nova Science Publishers, Inc.

Jacob, B.A. (2016). The opportunities and challenges of digital learning. Retrieved March 20, 2019, from https://www.brookings.edu/research/the-opportunities-and-challenges-of-digital-learning/

Keohane, N. O. (2013). Higher education in the twenty-first century: Innovation, adaptation, preservation. PS, Political Science \& Politics, 46(1), 102-105. doi: http://dx.doi.org/10.1017/S1049096512001734 
Köse, U. (2010). A blended learning model supported with Web 2.0 technologies. Procedia - Social and Behavioral Sciences, 2(2), 2794-2802, doi:10.1016/j.sbspro.2010.03.417

Lear, J. L., Isernhagen, J. C., LaCost, B. A., \& King, J. W. (2009). Instructor presence for web-based classes. Delta Pi Epsilon Journal, 51(2), 86-98. Retrieved from http://search.proquest.com.er.lib.k-state.edu/docview/195592989?accountid=11789

Liyan, S., Singleton, E., Hill, J., \& Koh, M. (2004). Improving online learning: Student perceptions of useful and challenging characteristics. Retrieved from https://doi.org/10.1016/j.iheduc.2003.11.003

Norman, S. (2016). 5 Advantages of Online Learning: Education without Leaving Home. eLearning Industry [online]. Retrieved from: https://goo.gl/jzzyUV

Popovici, A., \& Mironov, C. (n.d.) Students' perception on using eLearning technologies. Retrieved from https:/www.sciencedirect.com/science/article/pii/S1877042815016468

Rothrauff, L. (2011). Blended learning: What is it and why try it? Retrieved from http://ets.berkeley.edu/article/blended-learning-what-it-and-why-try-it

Simonson, M., Smaldino, S., Albright, M., \& Zvacek, S. (2003). Teaching and Learning at a Distance: Foundations of Distance Education (2nd ed.). Upper Saddle River, New Jersey: Pearson Education, Inc.

Sorden, S., \& Munene, I. (2013). Constructs related to community college student satisfaction in blended learning. Journal of Information Technology Education, 12251-270.

Torrisi-Steele, G., \& Drew, S. (2013). The literature landscape of blended learning in higher education: the need for better understanding of academic blended practice. International Journal for Academic Development, 18(4), 371-383. doi:10.1080/1360144X.2013.786720

Valenti, M. (2015). Beyond Active Learning: Transformation of the Learning Space. EDUCAUSE Review, 50(4). Retrieved September 24, 2015. 